\title{
Percutaneous Coronary Intervention in Nonagenarians: Prevalence, Indications, Vascular Approach and Mortality at 3 Months
}

\author{
Vincent Spagnoli, Quentin de Hemptinne, Mohamed Nosair and Gilbert Gosselin*
}

Department of Cardiology, Montreal Heart Institute, 5000 Belanger Street, Montreal, Quebec, H1T 1C8, Canada

\begin{abstract}
Background: Percutaneous coronary intervention $(\mathrm{PCl})$ in nonagenarians has been shown to be feasible, with a high success rate. However, there is paucity of data regarding the prevalence, vascular access, procedural data and mortality after $\mathrm{PCl}$ in this population.

Methods: All patients aged 90 and older referred to our institution from 2004 to 2014 for coronary angiogram were included in our retrospective study. Clinical and procedural data including vascular access and 3-month mortality rates were obtained for all patients.

Results: A total of $26696 \mathrm{PCl}$ were performed over the last 11 years, of which $177 \mathrm{PCl}(0.66 \%)$ were realized in 167 nonagenarians. The prevalence of $\mathrm{PCl}$ in nonagenarians increased from $0.17 \%$ in 2004 to $1.22 \%$ in 2014 . In this population, with an age of $92 \pm 2$ years and $51.4 \%$ of males, $76(43 \%) \mathrm{PCl}$ were performed in the setting of ST-elevation myocardial infarction, and $89(50 \%)$ of the procedures were non-ST elevation myocardial infarction or unstable angina. Transradial approach (TRA) was used in 76 (43\%) and transfemoral approach (TFA) in $101(57 \%)$ procedures. Comparing TRA to TFA, the total fluoroscopic time and contrast volume was similar between the two groups. Overall complications, including cardiogenic shock, iatrogenic coronary dissection, perforation or no reflow phenomenon occurred in 22 of 177 procedures (12.4\%). Overall survival rate was $92.8 \%$ at 3 months.
\end{abstract}

Conclusion: The majority of the procedures was performed in acute coronary syndrome clinical setting. TRA and TFA were comparable in terms of fluoroscopic time and contrast volume. Overall procedural success rate was high and complication rates were low.

Keywords: Nonagenarian; Percutaneous coronary intervention; Vascular access; Mortality

\section{Introduction}

Elderly population is growing in industrialized countries and cardiovascular diseases represent their first cause of morbidity and mortality [1]. Also, a non-negligible proportion of these patients is still autonomous. Therefore, cardiologists are more frequently confronted with management decisions involving elderly population, including nonagenarians. This frail subgroup of patients is often characterized by cardiovascular atypical symptoms and more comorbidities. Age is not a contraindication to perform coronary angiography and percutaneous coronary intervention (PCI). The first reported PCI series involving octogenarians was published in 1996 [2]. Later on, Cohen et al. showed that long-term outcome after PCI of octogenarian population was similar to the general population [3]. A recent publication by From et al. reported a series of PCI in nonagenarians and demonstrated that PCI was feasible and might provide benefits when clear indications were present [4]. However, what was true 10 years ago is all the more so today: randomized controlled trials of acute coronary syndrome continue to exclude or underrepresent very old patients [5].

In this study, we evaluated retrospectively 11 years of PCI practice in nonagenarian patients in a high volume center. We examined the prevalence, indications, vascular approach, safety, complications and mortality rates at 3 months.

\section{Methods}

\section{Population}

This is a single center cohort study performed at the Montreal Heart Institute, Montreal, Quebec, Canada, a reference center for cardiovascular disease management. From January 2004 to December
2014, all patients aged 90 and older referred to our institution for coronary angiography and PCI were included in our analysis. Data was extracted retrospectively and each angioplasty was reviewed in detail regarding: indications for PCI, vascular access site, fluoroscopic time and total volume of contrast media. Cardiogenic shock was defined as prolonged systolic blood pressure $<90 \mathrm{~mm} \mathrm{Hg}$, the need for inotropes or use of intra-aortic balloon pump. Vascular complications and 3 -month mortality rate data were collected. This study was approved by the local ethics committee.

\section{Procedures}

All the procedures were performed according to current international guidelines. Transradial approach (TRA) or transfemoral approach (TFA) was performed at the discretion of the operator. Barbeau test was systematically performed and had to be normal before the use of TRA. At the end of the PCI and after sheath removal from radial artery, a wrist compression device was used (TR Band, Terumo Medical Corporation, Somerset, NJ, United States). Manual compression was performed when TFA was realized, if closure devices

*Corresponding author: Gilbert Gosselin, Department of Cardiology, Montrea Heart Institute, 5000 Belanger Street, Montreal, Quebec, H1T 1C8, Canada, Tel: +1514-376-3330; Fax: +1514- 376-6299; E-mail: gilbert.gosselin@icm-mhi.org

Received February 16, 2016; Accepted March 11, 2016; Published March 17 2016

Citation: Spagnoli V, de Hemptinne Q, Nosair M, Gosselin G (2016) Percutaneous Coronary Intervention in Nonagenarians: Prevalence, Indications, Vascular Approach and Mortality at 3 Months. J Cardiovasc Dis Diagn 4: 239. doi:10.4172/2329-9517.1000239

Copyright: @ 2016 Spagnoli V, et al. This is an open-access article distributed under the terms of the Creative Commons Attribution License, which permits unrestricted use, distribution, and reproduction in any medium, provided the original author and source are credited. 
Citation: Spagnoli V, de Hemptinne Q, Nosair M, Gosselin G (2016) Percutaneous Coronary Intervention in Nonagenarians: Prevalence, Indications, Vascular Approach and Mortality at 3 Months. J Cardiovasc Dis Diagn 4: 239. doi:10.4172/2329-9517.1000239

Page 2 of 4

seemed unsafe to use. PCI success was defined as final TIMI 3 flow and $<30 \%$ residual diameter stenosis in the culprit artery. Volume of contrast media and total fluoroscopy time during PCI were collected to compare TRA versus TFA.

\section{Statistical Analysis}

Statistical analysis was performed using Graph Pad Prism 5. Continuous variables are expressed as mean \pm standard deviation. Paired and unpaired samples t-test were used to analyze differences in continuous variables with normal distribution. Categorical variables are expressed as frequencies and percentage. Chi-square and Fisher exact test were used for the comparison of categorical variables. A p-value $<0.05$ was considered significant.

\section{Results}

\section{PCI Prevalence and demographics characteristics}

26696 PCI were performed over the last 11 years in our institution and 177 PCI $(0.66 \%)$ were realized in 167 nonagenarians. The prevalence of PCI in nonagenarians increased from $0.17 \%$ in 2004 to $1.22 \%$ in 2014 (Figure 1). In this population, mean age of $92 \pm 2$ years, $51.4 \%$ of male, previous coronary revascularization was present in 44 (24.9\%), either PCI and / or CABG (Table 1 ).

\section{Indication for PCI}

Primary PCI for ST-elevation myocardial infarction (STEMI) was realized in 76 cases (43\%). Urgent PCI for non ST elevation myocardial infarction (NSTEMI) and / or unstable angina represented 48 (27\%) and $41(23 \%)$ cases respectively. Elective PCI was performed only in 12 cases (7\%) (Figure 2).

\section{Procedural characteristics}

The prevalence of TRA increased over the last 11 years (Figure 3 ). The TRA was used in 76 (43\%) (right radial artery in 74 cases) and the TFA in 101 (57\%) of the procedures. Bare metal stents (BMS) were more frequently implanted than drug eluting stents (DES): $82 \%$ versus $11 \%$ respectively (Table 2 ).

\section{Procedural success and complications}

Coronary procedural success was achieved in 166 procedures (93.7\%). Access site complications were noted in 3 cases $(1.7 \%)$ following PCI. Overall complications occurred in 19 of the procedures (11\%) including cardiogenic shock $(n=7)$, acute ventricular septal defect $(n=1)$, iatrogenic coronary dissection $(n=4)$, coronary perforation $(n=2)$ or no reflow $(n=5)$. Three-month mortality was $9 \%$ (15 patients). Amongst these 15 patients, 9 deaths (60\%) occurred following a STEMI.

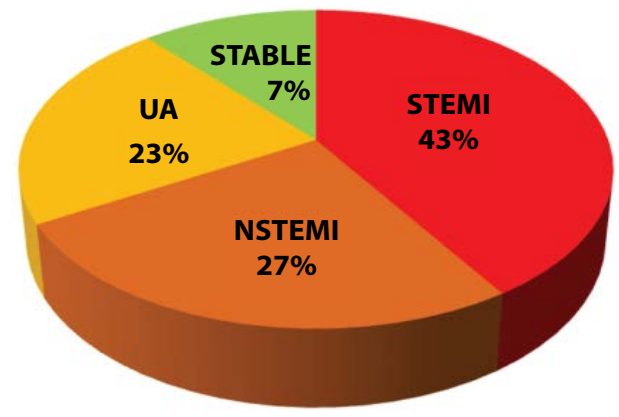

Figure 1: Clinical presentation.

\begin{tabular}{|c|c|}
\hline Variable & Patients $(\mathrm{n}=167)$ \\
\hline Age, years & $92 \pm 2$ \\
\hline Male gender, $\%$ & 51.4 \\
\hline Diabetes, $\%$ & 23.5 \\
\hline Hypertension, $\%$ & 57.8 \\
\hline Hypercholesterolemia, $\%$ & 61.9 \\
\hline Smoker or former smoker, $\%$ & 15.1 \\
\hline Familial history of CAD, $\%$ & 8 \\
\hline BMI, kg/m ${ }^{2}$ & $24.8 \pm 4.5$ \\
\hline Prior PCl, $\%$ & 16 \\
\hline Prior CABG, $\%$ & 14 \\
\hline
\end{tabular}

BMI: Body Mass Index; CAD: Coronary Artery Disease; PCl: Percutaneous Coronary Intervention; CABG: Coronary Artery Bypass Grafting.

Table 1: Baseline clinical characteristics.

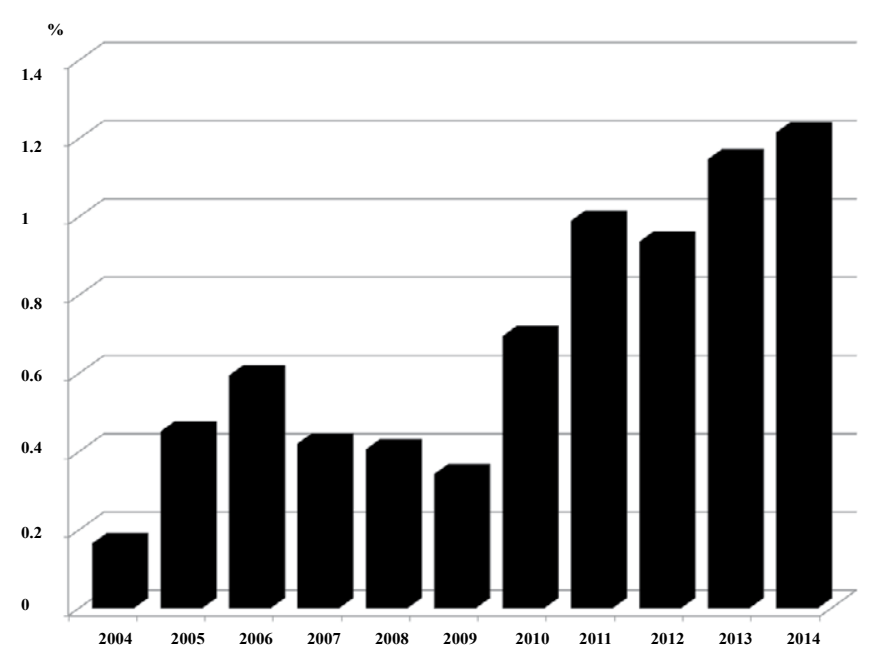

Figure 2: Prevalence of $\mathrm{PCl}$ in nonagenarians over 10 years.

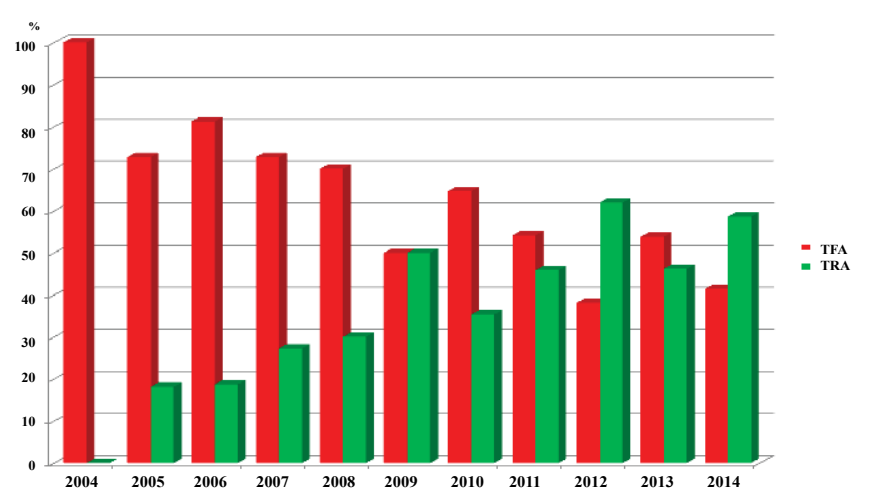

Figure 3: Prevalence of TFA and TRA in nonagenarians over 10 years.

\section{TRA versus TFA}

When comparing TRA to TFA, the total fluoroscopic time was not different: $14.4 \pm 1 \mathrm{~min}$ vs $16 \pm 1.1 \mathrm{~min}(\mathrm{p}=0.26)$ respectively and the contrast volume did not differ between the two groups: $186 \pm 6 \mathrm{ml}$ vs $199 \pm 8 \mathrm{ml}(\mathrm{p}=0.20)$. Coronary procedural success was achieved in 71 procedures (93\%) via the TRA and in 95 procedures $(94 \%)$ via the TFA $(\mathrm{p}=0.51)$ (Table 3$)$. Reported access sites complications were 1 radial dissection, 1 radial hematoma and 1 femoral hematoma. 


\begin{tabular}{|c|c|}
\hline Procedural finding, $\mathbf{n}(\mathbf{\%})$ & Procedures (n=177) \\
\hline Radial approach & $76(43 \%)$ \\
\hline Number of vessel coronary disease & \\
\hline 1 & $46(26 \%)$ \\
\hline 2 & $43(24 \%)$ \\
\hline 3 & $88(50 \%)$ \\
\hline Vessel treated & $16(9 \%)$ \\
\hline Cx & $80(45 \%)$ \\
\hline RCA & $67(38 \%)$ \\
\hline LAD & $14(8 \%)$ \\
\hline Left main & $9(5 \%)$ \\
\hline Saphenous vein graft & $149(84 \%)$ \\
\hline Predilation & $6(3.3 \%)$ \\
\hline Rotablator use & $145(82 \%)$ \\
\hline Coronary stenting & $20(11 \%)$ \\
\hline Bare metal stent & $12(7 \%)$ \\
\hline Drug eluting stent & \\
\hline Balloon angioplasty & \\
\hline
\end{tabular}

Cx: Circumflex; RCA: Right Coronary Artery; LAD: Left Anterior Descending Artery

Table 2: Angiographic and procedural characteristics.

\begin{tabular}{|c|c|c|c|}
\hline Variable & TRA $(\mathbf{n}=\mathbf{7 6})$ & TFA $(\mathbf{n}=\mathbf{1 0 1})$ & $\mathbf{P}$ \\
\hline Contrast volume, $\mathrm{ml}$ & $186 \pm 6$ & $199 \pm 8$ & 0.20 \\
\hline Fluoroscopic time, $\mathrm{min}$ & $14.4 \pm 1$ & $16 \pm 1.1$ & 0.26 \\
\hline $\mathrm{PCl}$ success, $\mathrm{n}(\%)$ & $71(93 \%)$ & $95(94 \%)$ & 0.51 \\
\hline
\end{tabular}

$\mathrm{PCl}$, Percutaneous Coronary Intervention. Data are expressed as mean and standard deviation.

Table 3: Transradial vs transfemoral approach.

\section{Discussion}

The main findings of this retrospective cohort are: 1) Prevalence of PCI in nonagenarians increased over the observation period of 11 years. 2) Urgent PCI was the most common indication to perform the procedure in the majority of cases. 3) TRA prevalence increased over the study period. 4) PCI success was achieved in the majority of cases. 5) Mortality at 3 months was low.

Current demographics in industrialized countries are reflected in the practice of interventional cardiology with an increase in the number of aging people addressed for coronary angiography and PCI [6]. The nonagenarians' paradox is represented by a growing population with a high prevalence of cardiovascular disease, more than the general population, but an underrepresentation in clinical trials and a lack of data regarding the best reperfusion strategy. In our series, there is a ten-fold increment of PCI in nonagenarian patients over the last 11 years. The prevalence increment could be explained by: 1) The possibility to perform coronary angiogram and PCI in safer conditions than previously. 2) Increment of aging population.

PCIs were realized in emergency in $93 \%$ of cases while only $7 \%$ were scheduled electively. Elective PCI, although rare 11 years ago, seems to be more frequent now due to enhancement of techniques and systematic angiography before trans-catheter aortic valve implantation. Urgent procedures were also predominant in other series studying PCI in nonagenarians: 92\% [7], 81.5\% [8] and $82 \%$ [9]. Despite the fact that primary PCI represents the best reperfusion therapy for STEMI patients, it concerns a minority of nonagenarians admitted for acute coronary syndrome. A conservative strategy is often adopted in hospitalized nonagenarian patients. Indeed, the rate of invasive management by primary PCI for STEMI was only $16.9 \%$ in a large national registry [10]. Numerous cohort studies suggested performing primary PCI in this population [11-14]. Recently, a large prospective registry on primary PCI compared demographics, angiographic data and outcome of nonagenarians (mean age $=92.9$ ) with non-nonagenarian patients (mean age $=61.7$ ). This study showed that PCI was feasible with a high success rate despite a higher shortterm mortality in nonagenarians $[15,16]$.

Large randomized controlled trials comparing TRA versus TFA in younger patients could be extended and also recommended to nonagenarians because of lower bleeding complications. A randomized trial compared TRA $(n=152)$ versus TFA $(n=155)$ in patients older than 75 years of age [17]. In this study, fluoroscopy time and amount of contrast agent were not different between the two strategies. Conversion of TRA to TFA was evaluated at $9 \%$. The rate of post procedural complications through TFA was found to be higher and thus the authors suggested to favor TRA. There is no randomized, prospective trial which compares TRA versus TFA in nonagenarians. Indeed, interventional cardiologists may feel uncomfortable with -TRA because of arterial stiffness and tortuosity, which are often present in aged and/or hypertensive patients. An experimental study has shown that elastin content is involved in the development of aneurysmal dilatation and tortuosity caused by marked decrease in longitudinal traction [18]. The overall elastin content decreases in the arterial wall of normal aging patients [19]. However, TRA, especially via the right radial artery, is feasible in the majority of cases, as reported in previous studies and in the present one. Some particular situations should be highlighted: left main management and patient in shock. In our study, left main was involved in 8 patients and was unprotected in 6 cases. All procedures were performed via TFA. The PCI was successfully achieved in 6 of them and was complicated in 2 patients: we reported 1 electro-mechanical dissociation pre-dilation and 1 cardiogenic shock on presentation. In such situations, TFA should be preferred for technical facilities and complication management.

In this very aged population, half of the patients had 3 vessels disease. Pre-dilation was performed in the majority of cases to optimize stent deployment. As a consequence of calcified coronary stenosis, the rate of rotational atherectomy was high (3.3\%), superior to the rate reported in some European Union countries [20]. BMS implantation was significantly higher than DES implantation. This is particularly true in the context of primary PCI, when medical history is unknown and bleeding complications can occur. The use of BMS in nonagenarians was recommended by the NINETY study [8]. Other current studies have reported a high success rate of PCI similar to the $94 \%$ of our series.

Because of the frailty of nonagenarians and the risk provided by coronary angiography and PCI, the patients are generally carefully selected. However, chest pain regression, symptom improvement, ischemic recurrence reduction and improvement in quality of life can easily be achieved by PCI [7]. Post PCI short term mortality was low in our series $(7.2 \%$ at three months) considering the fragility of these patients. This trend was consistent with the rate of $10 \%$ observed in other current series, in which risk factors associated with post PCI mortality are well described (left ventricular systolic dysfunction, diabetes, renal injury) and similar in nonagenarians except for the frequency $[21,22]$. The mean short term death rate of most of the current series regarding PCI in nonagenarians was $14 \%$ and one third of these studies concerned primary PCI during STEMI [23].

\section{Limitations}

This is a single center study and data were collected retrospectively. Therefore, some data regarding medical therapy, left ventricular 
Citation: Spagnoli V, de Hemptinne Q, Nosair M, Gosselin G (2016) Percutaneous Coronary Intervention in Nonagenarians: Prevalence, Indications, Vascular Approach and Mortality at 3 Months. J Cardiovasc Dis Diagn 4: 239. doi:10.4172/2329-9517.1000239

ejection fraction and mortality at one year are lacking. The prevalence and outcome of nonagenarian patients admitted for acute coronary syndrome treated medically or by surgery are not available. History of dementia and cerebrovascular events were not reported in our series. Unfortunately, frailty was not evaluated and patients admitted for PCI are probably highly selected. There was no difference in terms of rate of vascular complications between TRA and TFA, probably due to the small sample size.

\section{Conclusion}

Nonagenarian patients represent a growing section of our patients. Prevalence of $\mathrm{PCI}$ in this population has increased over the last 11 years. While most of the procedures were realized in an emergency setting, it has been demonstrated that PCI is safe and associated with a high success rate. Radial approach should be preferred because radiation and contrast level are similar when compared to femoral approach. The short term mortality rate was low and comparable to the general population.

\section{Conflict of Interest}

The authors have no conflicts of interest to declare.

\section{References}

1. Vincent GK, Velkoff VA (2010) The next four decades: The older population in the United States: 2010 to 2050 (No. 1138). US Department of Commerce, Economics and Statistics Administration, US Census Bureau.

2. Laster SB, Rutherford BD, Giorgi LV, Shimshak TM, McConahay DR, et al (1996) Results of direct percutaneous transluminal coronary angioplasty in octogenarians. Am J Cardiol 77: 10-13.

3. Cohen HA, Williams DO, Holmes DR Jr, Selzer F, Kip KE et al. (2003) Impact of age on procedural and 1-year outcome in percutaneous transluminal coronary angioplasty: a report from the NHLBI Dynamic Registry. Am Heart J 146: 513-519.

4. From AM, Rihal CS, Lennon RJ, Holmes DR Jr, Prasad A (2008) Temporal trends and improved outcomes of percutaneous coronary revascularization in nonagenarians. Cardiovasc Interv 1: 692-698.

5. Lee PY, Alexander KP, Hammill BG, Pasquali SK, Peterson ED (2001) Representation of elderly persons and women in published randomized trials of acute coronary syndromes. JAMA 286: 708-713.

6. Singh M, Rihal CS, Gersh BJ, Lennon RJ, Prasad A, et al. (2007) Twenty-fiveyear trends in in-hospital and long-term outcome after percutaneous coronary intervention: a single-institution experience. Circulation 115: 2835-2841.

7. Chait R, Zad O, Ramineni R, Shukla A, Mitchell A (2011) Midterm outcomes and quality of life following percutaneous coronary intervention in nonagenarians. Am J Cardiol 107: 1609-1612

8. Sillano D, Resmini C, Meliga E, Boccuzzi G, Zuffi A, et al. (2013) Retrospective multicenter observational study of the interventional management of coronary disease in the very elderly: the NINETY. Catheterization and Cardiovascular Interventions 82: 414-421.
9. Teplitsky I, Assali A, Lev E, Brosh D, Vaknin-Assa H, et al. (2007) Results of percutaneous coronary interventions in patients $\geq 90$ years of age. Catheterization and Cardiovascular Interventions 70: 937-943.

10. Mandawat A, Mandawat A, Mandawat MK (2013) Percutaneous coronary intervention after ST-segment elevation myocardial infarction in nonagenarians: use rates and in-hospital mortality. Journal of the American College of Cardiology 61: 1207-1208.

11. Danzi GB, Centola M, Pomidossi GA, Consonni D, De Matteis S, et al. (2010) Usefulness of primary angioplasty in nonagenarians with acute myocardial infarction. Am J Cardiol 106: 770-773.

12. Ionescu CN, Amuchastegui M, Ionescu S, Marcu CB, Donohue T (2010) Treatment and outcomes of nonagenarians with ST-elevation myocardial infarction. J Invasive Cardiol 22: 474-478.

13. Rigattieri S, Cera M, Sciahbasi A, Di Russo C, Fedele S, et al. (2013) Primary percutaneous coronary intervention in nonagenarians: six-month outcomes from a single-center registry. J Invasive Cardiol 25: 242-245.

14. Salinas P, Galeote G, Martin-Reyes R, Perez-Vizcayno MJ, Hernandez-Antolin $\mathrm{R}$, et al. (2011) Primary percutaneous coronary intervention for ST-segment elevation acute myocardial infarction in nonagenarian patients: results from a Spanish multicentre registry. Eurolntervention 6: 1080-1084.

15. Helft G, Georges JL, Mouranche X, Loyeau A, Spaulding C, et al. (2015) Outcomes of primary percutaneous coronary interventions in nonagenarians with acute myocardial infarction. Int J Cardiol 192: 24-29.

16. Petroni T, Zaman A, Georges JL, Hammoudi N, Berman E, et al. (2015) Primary Percutaneous Coronary Intervention for ST Elevation Myocardial Infarction in Nonagenarians: A Multicenter Study. Journal of the American Geriatrics Society 63: 84-386.

17. Achenbach S, Ropers D, Kallert L, Turan N, Krähner R, et al. (2008) Transradia versus transfemoral approach for coronary angiography and intervention in patients above 75 years of age. Catheterization and Cardiovascular Interventions 72: 629-635.

18. Dobrin PB, Schwarcz TH, Baker WH (1988) Mechanisms of arterial and aneurysmal tortuosity. Surgery 104: 568-571.

19. Wagenseil JE, Mecham RP (2012) Elastin in large artery stiffness and hypertension. J Cardiovasc Transl Res 5: 264-273.

20. Barbato E, Carrié D, Dardas P, Fajadet J, Gaul G, et al. (2015) European expert consensus on rotational atherectomy. Eurolntervention: journal of EuroPCR in collaboration with the Working Group on Interventional Cardiology of the European Society of Cardiology 11: 30-36.

21. Hendler A, Katz M, Gurevich Y, Reicher M, Blatt A, et al. (2011) 30-day outcome after percutaneous coronary angioplasty in nonagenarians: feasibility and specific considerations in different clinical settings. The Journal of invasive cardiology 23: 521-524.

22. Parikh R, Chennareddy S, Debari V, Hamdan A, Konlian D, et al. (2009) Percutaneous coronary interventions in nonagenarians: in-hospital mortality and outcome at one year follow-up. Clin Cardiol 32: E16-21.

23. Zoccai GB, Abbate A, D'Ascenzo F, Presutti D, Peruzzi M, et al. (2013) Percutaneous coronary intervention in nonagenarians: pros and cons. J Geriatr Cardiol 10: 82-90. 